\title{
The effect of gamma-irradiation on morphology and properties of melt-spun poly (lactic acid)/cellulose fibers
}

\author{
Tassadit Aouat a, ${ }^{\mathrm{a}}$, Mustapha Kaci a, José-Marie Lopez-Cuesta ${ }^{\mathrm{b}}$, Eric Devaux ${ }^{\mathrm{c}}$, \\ Mohamed Mahlous ${ }^{\mathrm{d}}$ \\ ${ }^{a}$ Laboratoire des Matériaux Polymères Avancés (LMPA), Faculté de Technologie, Université de Bejaia, 06000, Algeria \\ ${ }^{\mathrm{b}}$ Centre des Matériaux des Mines d'Alès (C2MA), École des Mines d'Alès, 6 avenue de Clavières, 30319, Alès Cedex, France \\ ${ }^{\mathrm{c}}$ École Nationale Supérieure des Arts et Industries Textiles (ENSAIT), GEMTEX, 9 rue de l'Ermitage, F-59100, Roubaix, France \\ ' Centre de Recherche Nucléaire d'Alger (CRNA), 2 Boulevard Frantz Fanon, Alger, 16000, Algeria
}

\begin{abstract}
A B S T R A C T
The effect of gamma irradiation on both morphology and properties of neat poly(lactic acid) (PLA), PLA/ microcrystalline cellulose (MCC) and PLA/cellulose nanowhiskers (CNW) fibers loaded at $1 \mathrm{wt} \%$ filler content was investigated in presence of PLA-grafted maleic anhydride (PLA-g-MA) used as the compatibilizer. Multifilament yarns were prepared by a melt-spinning process and subjected to gamma irradiation at various doses from 5 to $30 \mathrm{kGy}$ keeping the dose rate at $1.92 \mathrm{kGy} / \mathrm{h}$ under ambient conditions. Chemical structure, morphology and property changes induced by gamma irradiation on the samples were evaluated by several techniques considering the filler aspect ratio effect. The results showed a doserelated increase in the scission index (SI) of the irradiated samples whatever the filler size, while thermal and tensile properties significantly decreased. However, the incorporation of cellulosic fillers in PLA fibers, in particular MCC, was found to hinder the radiolytic degradation process of the irradiated samples.
\end{abstract}

\section{Keywords:}

Fibers

Polylactide

Cellulosic fillers

Gamma irradiation

Degradation

\section{Introduction}

In the past decade, the field of synthetic fibers made of biodegradable polymers was the subject of many publications and still continues to attract researchers from both academia and industry [1]. Large surface area to volume ratio, flexibility and potential to be produced in large quantities are some of the advantages that make fibers available for many industrial applications [2]. One of the most promising synthetic biodegradable polymers is poly(lactic acid) (PLA). PLA can be produced in fibrous structures with distinct fibers properties via melt spinning, solution spinning or electrospinning processes [3]. Based on the features of bioresorption and biocompatibility, PLA fibers are used for applications such as medical materials involving sutures, support for tissue engineering and three dimensional scaffolds [4]. Furthermore, a suitable modification of PLA in order to increase its mechanical properties would allow the extension of its utilization in many other application fields (textile structures, engineering materials, etc.). In this

\footnotetext{
* Corresponding author

E-mail address: samiaaouat@yahoo.ft (T. Aouat).
}

context, polymer nanocomposites are considered as potentially interesting to produce fibers with improved properties [5]. Nanofillers such as carbon nanotubes (CNT) [6,7], modified clays [5,8,9] and hydroxyapatite (HA) [10] were incorporated in PLA fibers to modulate the functional properties of PLA fibers such as thermal stability, mechanical properties, electrical and thermal conductivity performances [11]. In the same topic, nanocellulosic materials have undergone rapid development in recent years as promising fillers for polymeric matrices. Widespread interest of these materials was centered on their availability at low cost, biodegradability, biocompatibility, bioresorbability, outstanding mechanical properties, sustainability, and low cytotoxicity [12]. So far, many researchers investigated the fabrication techniques as well as the structure/properties relationships of PLA/cellulose nanowhiskers (CNW) fibers. The literature survey reveals that the preparation of these systems is restricted to those involving wet processing such as electrospinning which was extensively investigated [13-17] compared to melt spinning $[18,19]$. The main conclusion that can be drawn from these studies was that processing such a system is always difficult due to the poor compatibility between the hydrophilic CNW and the hydrophobic PLA matrix, and to a high tendency of nanocellulose to aggregate when dried. In a previous 
paper [11], fibers based on PLA/cellulose nanowhiskers (CNW) and PLA/microcrystalline cellulose (MCC) were prepared by meltspinning process at filler contents of 1 and $3 \mathrm{wt} \%$. Further, the effects of filler content and their aspect ratio during the spinning process as well as the fiber properties were evaluated. The results indicated that better thermal stability, flame retardancy, and fiber tensile properties were achieved by adding $1 \mathrm{wt} \%$ of CNW in PLA compared with MCC due to better dispersion of the CNW within the PLA matrix.

Applications of PLA in medical field require a full sterilization or decontamination of the material prior to its use in order to protect it against possible microbial contamination [20-22]. In this regard, a few sterilization techniques are recommended for aliphatic polyesters, due to their sensitivity to moisture and degradation by hydrolysis $[4,23,24]$. Among them, gamma irradiation is one of the most suitable methods for sterilization of such products with high penetration ability [25]. Nevertheless, the challenge is to elaborate nanobiocomposite materials which remain stable without affecting mechanical and barrier properties as well as not resulting in toxicological side effects during both storage and medical usage. According to the literature [26,27], the exposure of PLA to gamma irradiation results in chain scissions, which occur through two main degradation mechanisms, i.e. backbone chain scission and chain scission by hydrogen abstraction. As a matter of fact, a considerable work was published on oxidative degradation of PLA fiber scaffolds under gamma irradiation [21,28-32], since PLA is largely used as electrospun fibers in regenerative medicine. The studies showed that the gamma irradiation of PLA up to $30 \mathrm{kGy}$ induces slight changes in the polymer properties. However at a higher dose, the decay of PLA molecular weight is the radiation-induced main effect and consequently, a decrease in the thermal and mechanical properties of irradiated PLA is observed. According to the open literature, there are only a very few reports dealing with the degradation of PLA nanocomposites under gamma irradiation, using as fillers mainly modified Montmorillonite (Cloisite 30B) [33,34], hydroxyapatite (HAP) [20,25] and ZnO [35]. Further, no published data are available yet on the effect of gamma irradiation on PLA/Cellulose nanowhiskers nanobiocomposites.

Therefore, the objective of this work was to investigate the effect of gamma irradiation at lower doses ranging from 0 to $30 \mathrm{kGy}$, on the morphology, thermal and mechanical properties of nanobiocomposites based on PLA/CNW and PLA/MCC fibers prepared by melt spinning at $1 \mathrm{wt} \%$ loading rates. In this study, the filler content of $1 \mathrm{wt} \%$ was selected as an outcome of an optimization procedure, which was clearly reported in our previous work devoted to the elaboration and characterization properties of PLA/Cellulose fibers prepared by melt spinning [11].

\section{Experimental}

\subsection{Materials}

PLA used was fiber-grade resin 6202D supplied by Nature Works LLC. According to the manufacturer, the polymer has a density of $1.24 \mathrm{~g} / \mathrm{cm}^{3}$, a glass transition temperature $\left(T_{g}\right)$ of about $60^{\circ} \mathrm{C}$, and a melting point ranged from 160 to $170^{\circ} \mathrm{C}$.

Microcrystalline cellulose (MCC) was supplied by Sigma-Aldrich under the trade name Avicel PH 101. Cellulose nanowhiskers (CNW) were extracted from MCC through sulfuric acid hydrolysis, in aqueous media, according to the literature data [36].

\subsection{Preparation of PLA/Cellulose nanobiocomposites}

Neat PLA and PLA nanobiocomposite fibers were manufactured using a two-step process. The first step was the preparation of the samples pellets by a Thermo-Haake co-rotating intermeshing twinscrew extruder $(\mathrm{L} / \mathrm{D}=25)$ according to the compositions reported in Table 1. Then, the extruded materials were used to obtain the multifilament fibers using a melt-spinning machine, Model Spinboy I, manufactured by Busschaert Engineering. The elaboration of PLA fibers has been detailed in a recent paper [11].

\subsection{Gamma irradiation test}

The fibers of neat PLA and PLA/Cellulose nanobiocomposites were irradiated in ${ }^{60} \mathrm{Co}$ gamma irradiation facility at the Nuclear Research Center of Algiers. All samples were irradiated at a constant dose rate of $1.92 \mathrm{kGy} / \mathrm{h}$ in air at room temperature at various doses, i.e. $5,10,15,20,25$ and $30 \mathrm{kGy}$.

\subsection{Characterization methods}

\subsubsection{Molecular weight changes}

The variation of the molecular weight of the samples as a function of the absorbed dose was determined by viscosity measurements. The chloroform was used as solvent in an Ubbelohde type capillary viscometer immersed in a water bath at $30 \pm 0.5^{\circ} \mathrm{C}$. The Huggins equation was applied to estimate the intrinsic viscosity $[\eta]$, which is related to the viscosity average molecular weight $\left(\overline{\mathrm{M}_{\mathrm{V}}}\right)$ by the Mark-Houwink-Sakurada equation (1):

$[\eta]=K \cdot \bar{M}_{\mathrm{v}}^{\mathrm{a}}$

Where the constants $\mathrm{K}$ and a, calculated for the PLA/chloroform system at $30^{\circ} \mathrm{C}$ are $\mathrm{K}=1,31.10^{-4} \mathrm{dl} / \mathrm{g}$ and $\mathrm{a}=0,759$ [37].

The extent of radiation-induced degradation of the nanobiocomposite fibers is determined from the number of main-chain scission index (SI). SI is defined according to the following eq. (2) [38]:

$\mathrm{SI}=\left[\overline{\mathrm{M}}_{\mathrm{v} 0} / \overline{\mathrm{M}}_{\mathrm{v}}\right]-1$

Where $\overline{\mathrm{M}}_{\mathrm{v} 0}$ and $\overline{\mathrm{M}_{\mathrm{v}}}$ are the viscosity-average molecular weight before and after $\gamma$-irradiation.

\subsubsection{Fourier transform infrared spectroscopy (FT-IR)}

The chemical changes due to gamma irradiation were monitored by FT-IR spectroscopy using a Bruker IFS66 FTIR spectrometer (Golden Gate reflection system; Bruker, Karlsruhe, Germany). The FTIR spectra were measured with a resolution of $2 \mathrm{~cm}^{-1}$ and an accumulation of 64 scans using a standard pike attenuated total reflectance (ATR). The spectra were scanned in the range starting from 400 to $4000 \mathrm{~cm}^{-1}$.

\subsubsection{Tensile measurements}

The measurements of the tensile properties of the samples were carried out on twisted fibers ( 80 monofilaments). A mechanical tester system MTS associated with a force sensor of $1 \mathrm{kN}$ was used. In order to adjust clamp load and to grip the sample with the least amount of stress, a special design for testing yarns was used (capstan grips). Capstan roller in addition to vise action allows the sample to be both clamped at the desired level and to be wound

Table 1

Summary of PLA fiber composition.

\begin{tabular}{lllll}
\hline Fibers & PLA (wt\%) & PLA-g-MA (wt\%) & MCC (wt\%) & CNW (wt\%) \\
\hline PLA & 100 & 0 & 0 & 0 \\
PLA/PLA-g-MA/CNW1 & 92 & 7 & 0 & 1 \\
PLA/PLA-g-MA/MCC1 & 92 & 7 & 1 & 0 \\
\hline
\end{tabular}


Table 2

Viscosity average molecular weight against $\gamma$-radiation dose for the fibers.

\begin{tabular}{llll}
\hline \multirow{2}{*}{ Dose $(\mathrm{kGy})$} & \multicolumn{3}{l}{ Viscosity average molecular weight $\left(\overline{\boldsymbol{M}_{\boldsymbol{v}}}\right)(\mathrm{g} / \mathrm{mol})$} \\
\cline { 2 - 4 } & PLA & PLA/PLA-g-MA/MCC1 & PLA/PLA-g-MA/CNW1 \\
\hline 0 & 42,000 & 30,000 & 35,000 \\
5 & 36,000 & 27,000 & 30,000 \\
10 & 32,000 & 25,000 & 26,000 \\
15 & 27,000 & 25,000 & 26,000 \\
20 & 24,000 & 24,000 & 24,000 \\
25 & 20,000 & 23,000 & 22,000 \\
30 & 18,000 & 21,000 & 20,000 \\
\hline
\end{tabular}

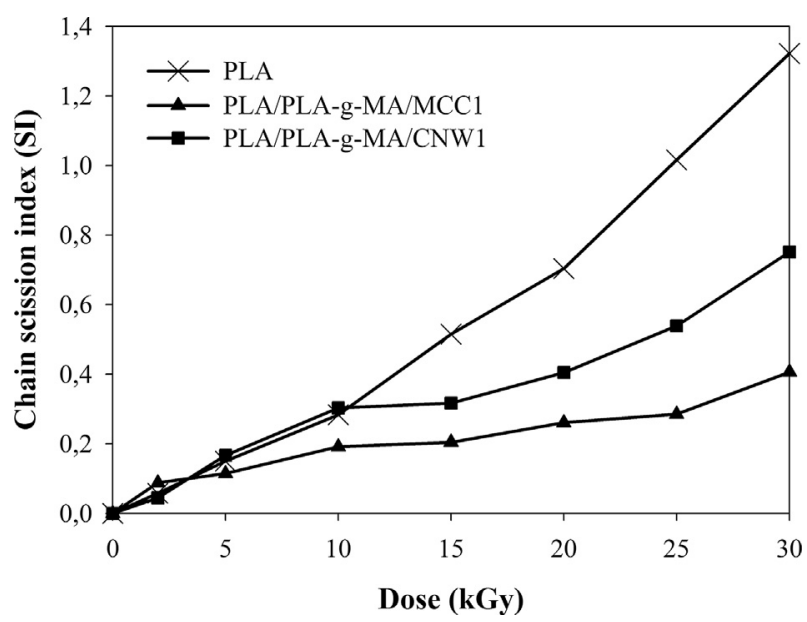

Fig. 1. Chain scission index (SI) versus dose for neat PLA, PLA/PLA-g-MA/CNW1 and PLA/PLA-g-MA/MCC1 fibres.

around the capstan to distribute the remaining stress via friction. The tensile properties were measured according to the ISO 2062 standard test method. A loading speed of $200 \mathrm{~mm} / \mathrm{min}$ and a distance of $200 \mathrm{~mm}$ between grips were applied. All mechanical tests were carried out by using specimens previously conditioned for at least $48 \mathrm{~h}$ at $20 \pm 2{ }^{\circ} \mathrm{C}$ under a relative humidity of $50 \pm 3 \%$. The values were averaged out over five measurements for each sample.

Because of the variation in the fibers fineness, the tensile strength is expressed as tenacity ( $\mathrm{cN} / \mathrm{tex}$ ), a specific value related to fineness (force per unit fineness). Fineness in tex $(\mathrm{g} / \mathrm{km})$, was determined by dividing the mass of fibers by their known length [39].

\subsubsection{Differential scanning calorimetry (DSC)}

DSC thermograms of each fiber, before and after irradiation, were performed using a 2920 Modulated DSC (TA Instruments). The dried samples of an average weight of about $10 \mathrm{mg}$ were placed in hermetically closed DSC devices under nitrogen atmosphere with a flow rate of $50 \mathrm{ml} / \mathrm{min}$. The heating and cooling steps were carried out at a rate of $10^{\circ} \mathrm{C} / \mathrm{min}$ from 20 to $200^{\circ} \mathrm{C}$ and from 200 to $20^{\circ} \mathrm{C}$, respectively. Thermal properties, i.e. glass transition temperature $\left(T_{g}\right)$, cold crystallization temperature $\left(T_{c c}\right)$ and melt temperature $\left(\mathrm{T}_{\mathrm{m}}\right)$ were determined from the second heating cycle of the samples. The crystalline index $\left(\mathrm{X}_{\mathrm{C}}\right)$ was calculated according to eq. (3) [25]:

$X_{c}(\%)=\frac{\Delta H_{m}-\Delta H_{c c}}{W . \Delta H_{m 0}} .100$

Where, $\Delta \mathrm{H}_{\mathrm{m}}$ is the melting enthalpy of the sample, $\Delta \mathrm{H}_{\mathrm{m} 0}$ is the melting enthalpy of a $100 \%$ crystalline PLA, taken as $93 \mathrm{~J} / \mathrm{g}$ [40]. $\Delta \mathrm{H}_{\mathrm{cc}}$ is the crystallization enthalpy and $\mathrm{W}$ is the weight fraction of PLA in the nanobiocomposite fiber.

\subsubsection{Thermogravimetric analysis (TGA)}

Thermogravimetric analysis (TGA) was performed on a Perkin Elmer Pyris-1 TGA thermo-balance (PerkinElmer, Waltham, MA, USA) operating under air in alumina crucibles containing around $10 \pm \mathrm{mg}$ of material and ranging from 30 to $900^{\circ} \mathrm{C}$ at a heating rate of $10^{\circ} \mathrm{C} / \mathrm{min}$.

\subsubsection{Scanning electron microscopy (SEM)}

SEM images of the fibers were captured using a QUANTA 200 FEG (FEI Company) environmental scanning electron microscope at an acceleration voltage of $7-10 \mathrm{keV}$. Prior to any observation in scanning mode (SEM), the transversal surfaces of the fibers were sputter coated with carbon using a Carbon Evaporator Device
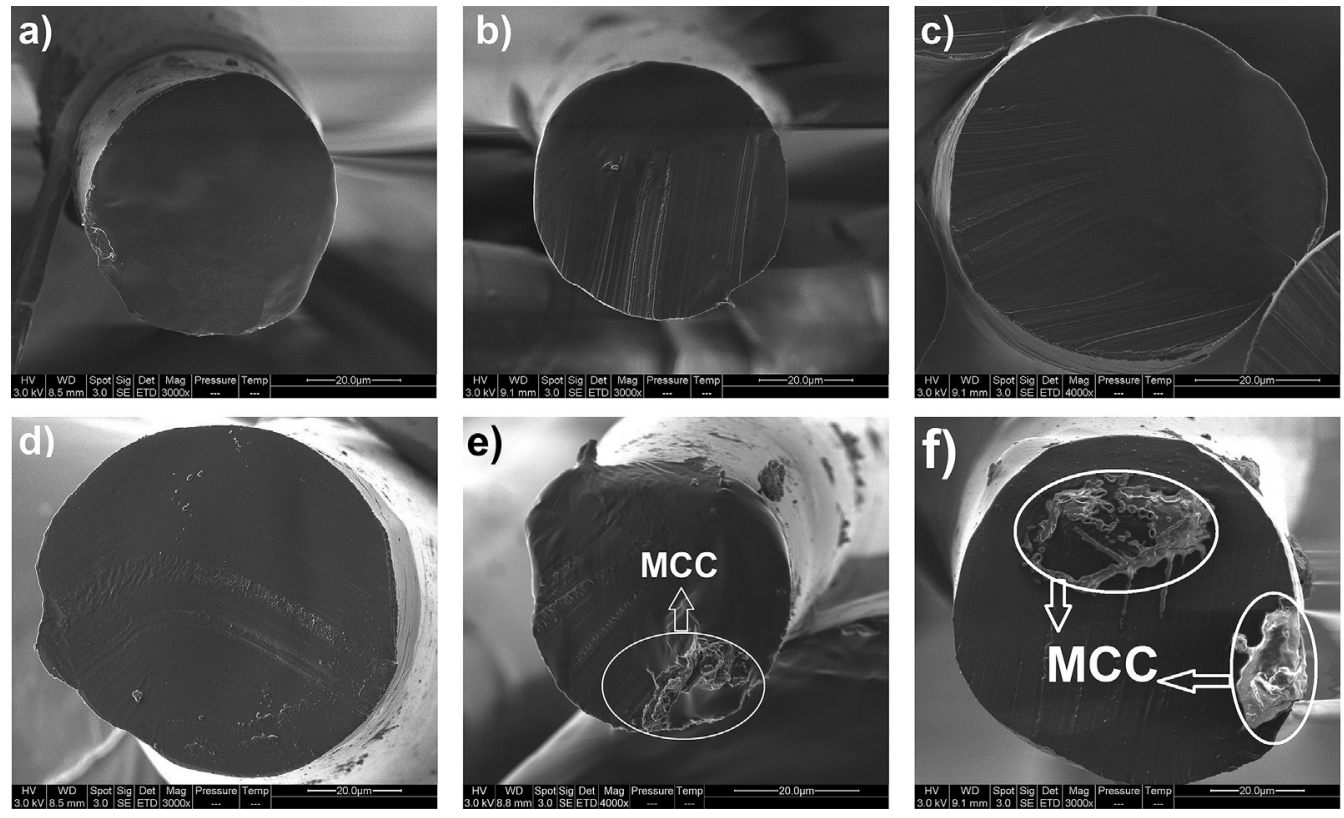

Fig. 2. SEM photographs of PLA (a, b), PLA/PLA-g-MA/CNW1 (c, d) and PLA/PLA-g-MA/MCC1 (e, f) before and after irradiation of 30 kGy, respectively. 
CED030 (Balzers), to ensure good surface conductivity and to avoid any degradation.

\subsubsection{Transmission electron microscopy (TEM)}

TEM observations were carried out on a JEOL 1200EX TEM scanning electron microscope operating at an accelerating voltage of $100 \mathrm{kV}$. The TEM samples were embedded in a LR white resin and ultrathin-sectioned at $70 \mathrm{~nm}$ using a Leica EM UC7 ultra-microtome with a diatome diamond knife Ultra 45 (Nissei Sangyo). The sections were transferred to carbon-coated $\mathrm{Cu}$ grids of 300 meshes.

\section{Results and discussion}

\subsection{Molecular weight changes}

According to the literature [41,42], $\gamma$-irradiation often results in molecular weight changes in irradiated polymers by decreasing or increasing the molecular weight due to chain scission or crosslinking, respectively depending on the absorbed dose. In this study, the molecular weight changes occurring in the irradiated fibers were determined through the viscosity average molecular weight $\left(\overline{\mathrm{M}_{\mathrm{V}}}\right)$ measurements. The results of reciprocal $\overline{\mathrm{M}_{\mathrm{v}}}$ are provided in Table 2. Furthermore, the chain scission index (SI) evolution as a function of absorbed dose is also plotted in Fig. (1). Data reported in Table 2 indicate a decay in $\overline{\mathrm{M}_{\mathrm{v}}}$ values for all irradiated fibers and subsequently, an increase is observed for SI with increasing the absorbed dose (Fig. 1). This means that there is a structural deterioration of the irradiated fibers resulting in the formation of products of low molecular weight over the dose range investigated $(5-30 \mathrm{kGy})[43,44]$. A probable explanation lies in the chain scission due to the radical formation, predominantly occurring in amorphous regions of PLA $[33,43,45]$. Indeed, the energy supplied by irradiation is absorbed by exposed material, and excited macromolecules are produced [33]. Therefore, the decrease in molecular weight is a consequence of the prevailing backbone chain scission, where long polymer backbone chains break into shorter ones $[43,45]$. The literature reported that PLA undergoes mainly chain-scission at doses below $250 \mathrm{kGy}[26,27,41-47]$. However at higher doses, crosslinking reactions increase with the radiation dose [48].

Moreover, Fig. (1) shows also that the presence of cellulosic fillers in PLA results in less decrease in $\overline{\mathrm{M}_{\mathrm{V}}}$ of the nanobiocomposite fibers compared to the neat PLA and subsequently, lower SI values. For instance at $30 \mathrm{kGy}$, the SI values determined for neat PLA, PLA/ PLA- $g$-MA/CNW1 and PLA/PLA- $g$-MA/MCC1 are about 1.3, 0.8 and 0.4 , respectively. The anti-oxidant activity of the nanobiocomposites could be associated with cross-linking of reactive species of cellulose and PLA produced during gamma irradiation process. As a result, a complex is formed between PLA and cellulose, and better bonding could occur between them [49]. As a matter of fact, $\gamma$-irradiation has been shown to be an effective method for improving the interfacial adhesion between cellulosic fillers and various matrices such as polypropylene (PP) [49], polycaprolactone (PCL) [50], bisphenol [51], gelatin [52] and ethylene-vinyl alcohol $(\mathrm{EVOH})$ [53].

Comparing the radiochemical degradation effect on both biocomposite samples, it can be observed that the one filled with MCC shows less damage than PLA/CNW. Indeed, the plot of SI versus absorbed dose shown in Fig. (1), exhibits lower evolution for PLA/ PLA-g-MA/MCC1 compared to that of PLA/PLA- $g-M A / C N W 1$. For instance at $30 \mathrm{kGy}$, the SI value recorded for PLA/PLA-g-MA/CNW1 is approximately 0.8 , against 0.4 for PLA/PLA-g-MA/MCC1 fibers. Further, this may also result from the crystalline structure of the microcrystalline cellulose, which acts as a shield for PLA.
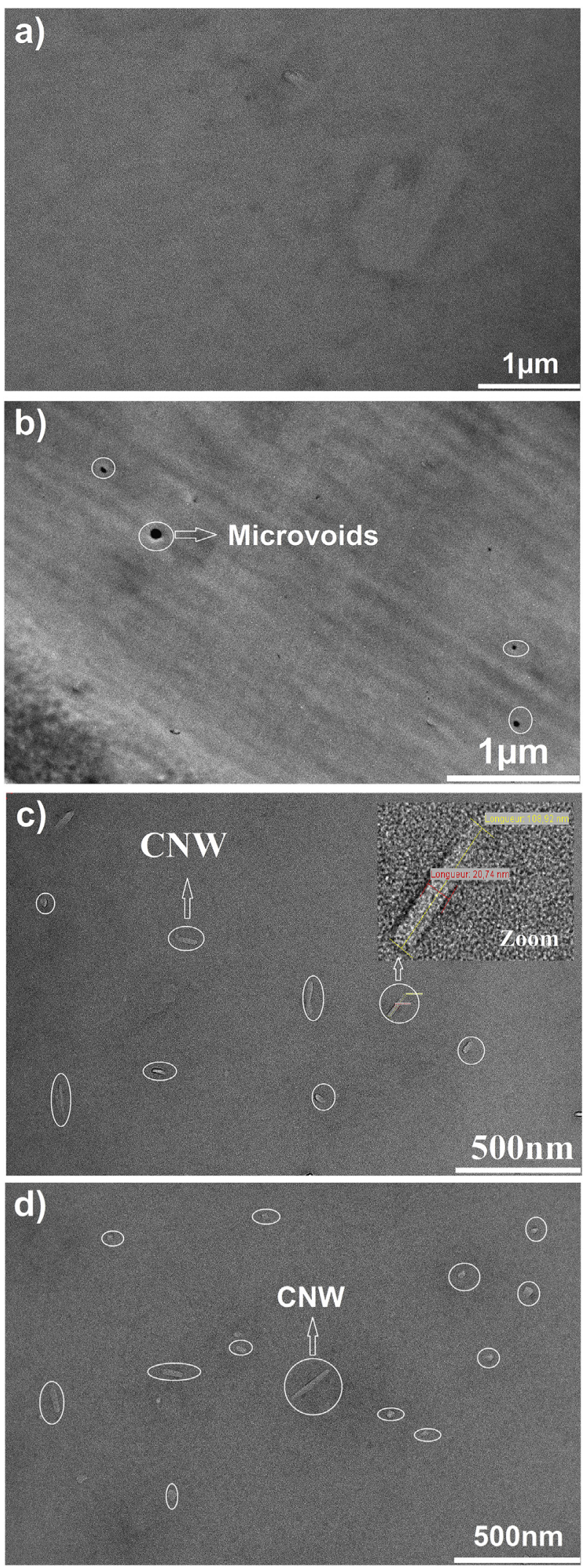

Fig. 3. TEM photographs of PLA (a, b) and PLA/PLA-g-MA/CNW1 (c, d) before and after irradiation of $30 \mathrm{KGy}$, respectively. 

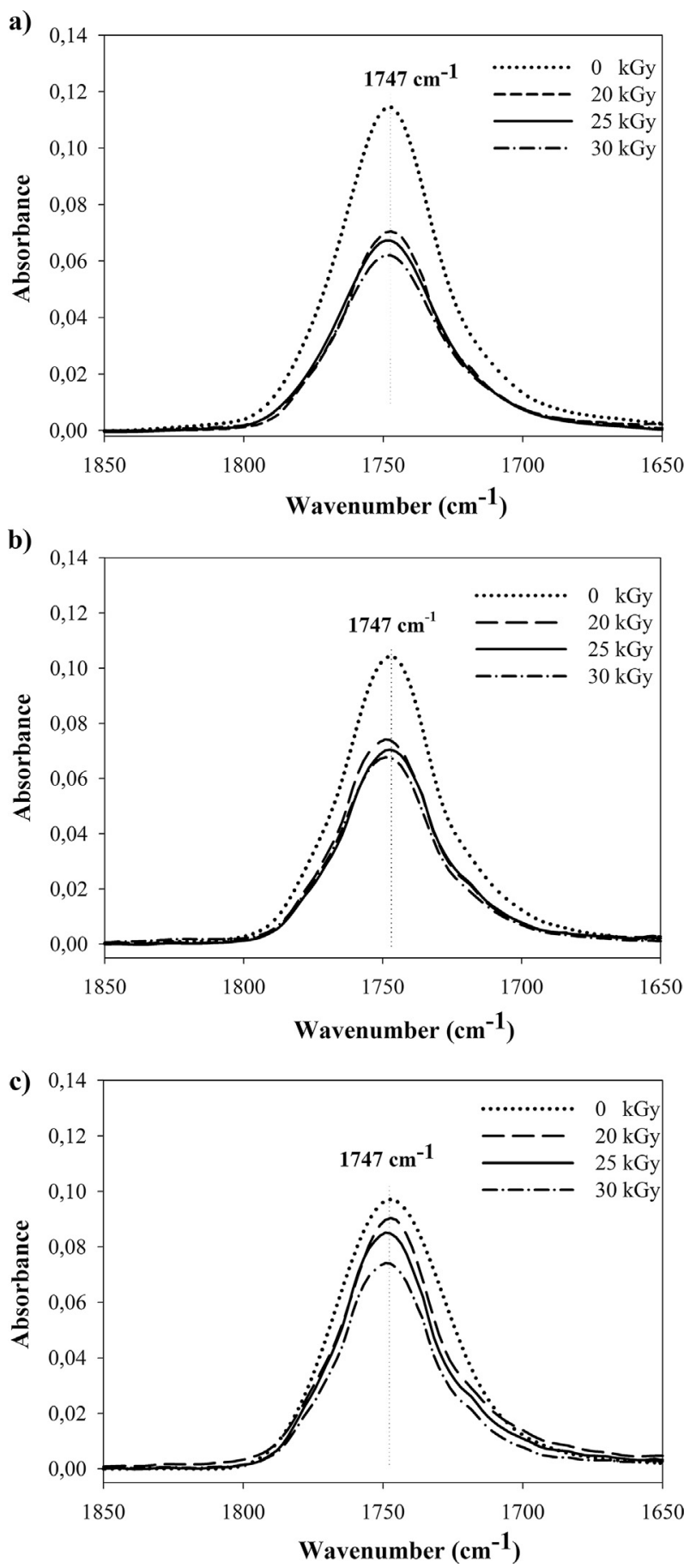

Fig. 4. Evolution of FTIR spectra of (a) neat PLA, (b) PLA/PLA- $g$-MA/CNW1 and (c) PLA/ PLA-g-MA/MCC1 at different $\gamma$-radiation doses in the domains $1850-1650 \mathrm{~cm}^{-1}$.

\subsection{Morphological analysis by SEM and TEM}

Morphology generally results from the complex thermomechanical history experienced by the different constituents during material processing [48]. Further, the structural modifications induced by ionizing radiation may also alter the morphology of the irradiated samples. In this respect, the morphology of samples was examined before and after $\gamma$-irradiation, using scanning electron microscope and transmission electron microscope. SEM images were taken on fiber's cross section. SEM and TEM micrographs of a)

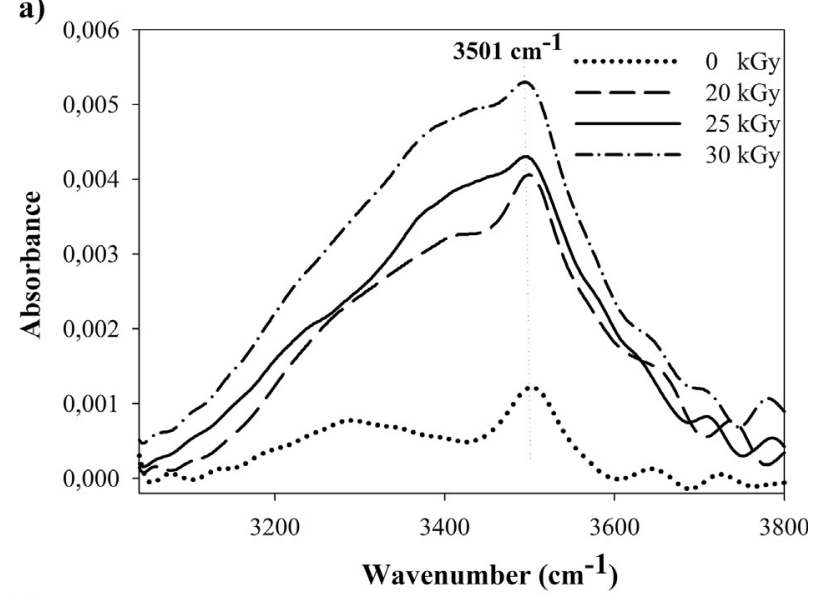

b)

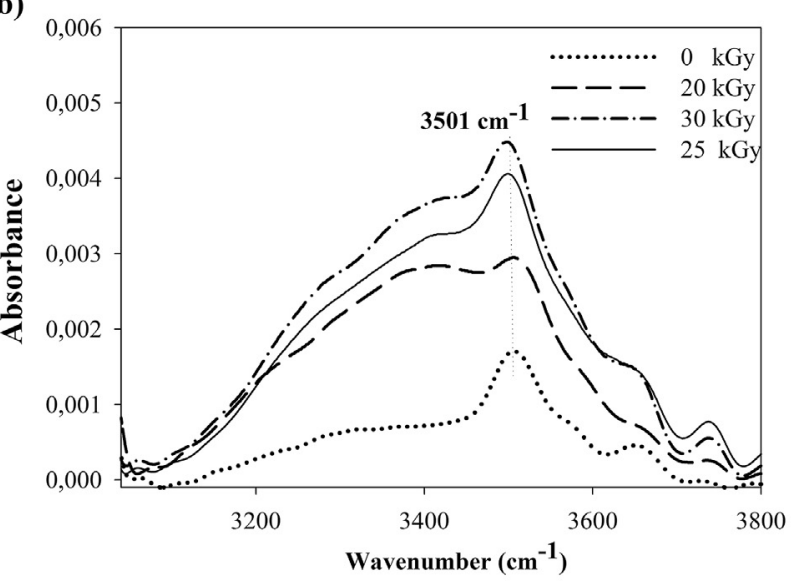

c)

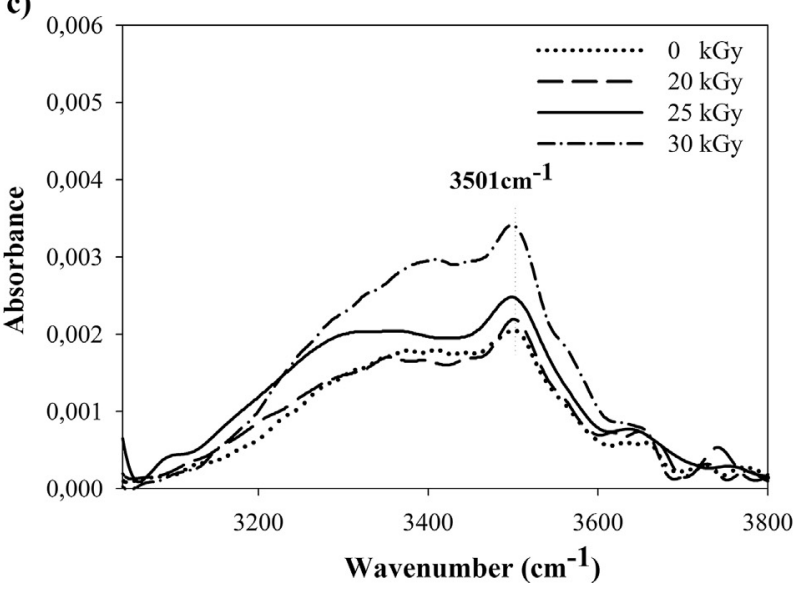

Fig. 5. FTIR spectra of (a) neat PLA, (b) PLA/PLA-g-MA/CNW1 and (c) PLA/PLA-g-MA/ MCC1 recorded at different doses in the domains $3000-3800 \mathrm{~cm}^{-1}$.

samples are shown in Figs. 2 and 3, respectively.

Figs. 2(a) and Fig. 3(a) show that the surface of neat PLA before $\gamma$-irradiation appears quite homogeneous and smooth. However at $30 \mathrm{kGy}$, the irradiated PLA exhibits a slightly rough morphology with some microvoids as illustrated in Fig. 3(b), probably caused by the release of radiolysis products. In addition, based on Fig. 2(c), (d) and Fig. 3(c), (d), it seems that PLA/PLA-g-MA/CNW1' morphology was not affected by the ionizing radiation. Indeed, cellulose nanowhiskers (CNW) still exhibit their initial whiteness and density. Likewise, no significant alteration was observed on the surface of PLA/PLA-g-MA/MCC1 fibers after irradiation, according to Fig. 2(f). 
Table 3

Tensile properties as a function of absorbed doses for neat PLA, PLA-PLA-g-MA/MCC1and PLA/PLA-g-MA/CNW1 fibers.

\begin{tabular}{|c|c|c|c|c|}
\hline Fibers & Dose (kGy) & Young modulus (GPa) & Tenacity (CN/tex) & Elongation at break (\%) \\
\hline \multirow[t]{7}{*}{ PLA } & 0 & $3.27 \pm 0.5$ & $7.74 \pm 0.2$ & $77.77 \pm 1.5$ \\
\hline & 5 & $3.26 \pm 0.1$ & $7.69 \pm 0.6$ & $77.84 \pm 0.9$ \\
\hline & 10 & $3.26 \pm 0.3$ & $7.61 \pm 0.7$ & $73.78 \pm 1.1$ \\
\hline & 15 & $3.21 \pm 0.1$ & $7.55 \pm 0.9$ & $72.91 \pm 1.3$ \\
\hline & 20 & $3.15 \pm 0.2$ & $7.39 \pm 0.1$ & $69.92 \pm 1.9$ \\
\hline & 25 & $2.70 \pm 0.7$ & $6.82 \pm 0.4$ & $57.84 \pm 0.8$ \\
\hline & 30 & $2.64 \pm 0.2$ & $5.74 \pm 0.2$ & $45.52 \pm 1.5$ \\
\hline \multirow[t]{7}{*}{ PLA/PLA-g-MA/MCC1 } & 0 & $2.94 \pm 0.5$ & $6.88 \pm 0.4$ & $36.46 \pm 1.1$ \\
\hline & 5 & $2.93 \pm 0.1$ & $6.80 \pm 0.6$ & $36.26 \pm 0.7$ \\
\hline & 10 & $2.94 \pm 0.2$ & $6.78 \pm 0.1$ & $36.34 \pm 0.3$ \\
\hline & 15 & $2.94 \pm 0.3$ & $6.84 \pm 0.2$ & $35.68 \pm 0.4$ \\
\hline & 20 & $2.93 \pm 0.2$ & $6.77 \pm 0.4$ & $36.15 \pm 1.1$ \\
\hline & 25 & $2.91 \pm 0.1$ & $6.67 \pm 0.2$ & $35.11 \pm 0.3$ \\
\hline & 30 & $2.92 \pm 0.5$ & $6.78 \pm 0.7$ & $36.81 \pm 0.9$ \\
\hline \multirow{7}{*}{ PLA/PLA-g-MA/CNW1 } & 0 & $3.38 \pm 0.2$ & $8.04 \pm 0.1$ & $91.60 \pm 0.8$ \\
\hline & 5 & $3.38 \pm 0.4$ & $8.05 \pm 0.7$ & $90.09 \pm 0.2$ \\
\hline & 10 & $3.35 \pm 0.7$ & $7.93 \pm 0.1$ & $91.08 \pm 1.1$ \\
\hline & 15 & $3.36 \pm 0.3$ & $7.88 \pm 0.3$ & $87.83 \pm 0.5$ \\
\hline & 20 & $3.34 \pm 0.1$ & $7.75 \pm 0.8$ & $88.15 \pm 1.1$ \\
\hline & 25 & $3.12 \pm 0.3$ & $7.21 \pm 0.9$ & $74.49 \pm 1.5$ \\
\hline & 30 & $2.91 \pm 0.1$ & $6.52 \pm 0.1$ & $65.22 \pm 1.9$ \\
\hline
\end{tabular}

These small morphological changes can be attributed to the moderate radiation dose applied on the fibers ( $30 \mathrm{kGy})$. Indeed, previous studies have shown that changes in the surface morphology of PLA with $\gamma$-irradiation are dose dependent and they are weakly evident for radiation doses up to $50 \mathrm{kGy}$, but quite clear for higher doses [4,47,54]. In this regard, D. Milicevic et al. [45] have demonstrated the formation of defect/damage and new lamellae in PLLA surface morphology after $200 \mathrm{kGy}$.

\subsection{FT-IR analysis}

$\gamma$-irradiation exposure often leads to changes in the characteristics of the material at almost all structural levels [45]. The chemical changes in the irradiated fibers based on PLA were evaluated by FT-IR spectroscopy. Representative FT-IR spectra of nonirradiated and irradiated samples recorded at 20, 25, and $30 \mathrm{kGy}$, in the carbonyl and hydroxyl regions are shown in Fig. (4) and (5), respectively.

Before exposure, all samples exhibit a well-defined absorption band at $\lambda_{\max }=1745 \mathrm{~cm}^{-1}$, in the carbonyl region as shown in Fig. 4(a), (b) and (c). This broad absorption band is assigned to ester group of PLA [55,56]. Upon exposure to $\gamma$-irradiation, a decrease in the absorption band intensity of ester group is observed for all irradiated samples, which is more pronounced at higher doses, especially for neat PLA (Fig. 4(a)). This suggests that chemical reactions have occurred in the PLA matrix resulting probably in chain scission as reported in literature [33].

FT-IR spectra recorded in the region $3800-3000 \mathrm{~cm}^{-1}$ (Fig. 5(a), (b) and (c)), show a broad absorption band centered approximately at $\lambda_{\max }=3501 \mathrm{~cm}^{-1}$, which corresponds to free $\mathrm{OH}$ groups present in alcohols, hydroperoxides and carboxylic acids [15,44]. Further, the absorption band intensity of $\mathrm{OH}$ groups is observed to increase with the radiation dose in both neat PLA and PLA nanobiocomposite samples. This result clearly indicates that the main oxidation process involved in $\gamma$-irradiation leads to the formation of hydroxyl groups [57]. This is consistent with the literature data reported by Madera-Santana et al. [44], Zaidi et al. [33] and Zembouai et al. [34] who demonstrated that the radiolysis of PLA backbone through its ester bond leads to the formation of carboxyl groups.

\subsection{Tensile measurements}

The absorbed dose effect on the mechanical properties of neat PLA and PLA/cellulose nanobiocomposites was evaluated by tensile measurements. The basic mechanical characteristics of fibers, i.e. tenacity, Young's modulus and elongation at break were determined and the values are summarized in Table 3. In addition, Fig. (6) shows the plot evolution of the relative tensile properties as a function of the absorbed dose for all irradiated samples being known that these relative characteristics are calculated based on the ratio between the value recorded at a given dose and the initial one.

From Table 3 and Fig. 6(a), (b) and (c), all the tensile properties seem to be stable up to almost $20 \mathrm{kGy}$. However beyond this dose, a gradual decrease in the tensile characteristics is observed resulting in brittle materials. Indeed after $30 \mathrm{kGy}$, Young's modulus, tenacity and elongation at break of irradiated neat PLA, illustrated in Fig. 6(a), have decreased by almost 25,26 and $42 \%$, respectively compared to the initial values. This is due probably to the structural changes induced by $\gamma$-irradiation in the PLA matrix, leading to chain scission and subsequently, to a reduction in the molecular weight [58]. This result is consistent with the literature data [33,34,47,48,54]. From Fig. 6(a), (b) and (c) and Table 3, it is noticed that the addition of $1 \mathrm{wt} \%$ of cellulosic fillers in PLA matrix results in discrepancies in the tensile characteristics of the nanobiocomposites as a function of the radiation dose. However, it has to be noted that all mechanical properties of PLA/PLA-g-MA/MCC1 are lower than those of the pristine PLA prior to irradiation. Conversely, all mechanical properties are improved for PLA/PLA-g-MA/CNW1. This can be ascribed to a reinforcing effect and a good dispersion of the cellulose nanowhiskers [11]. In contrast, as observed in SEM micrographs, microcrystalline cellulose exhibits agglomerates and due to the lowering of Young's modulus, it can be suggested that the agglomerates are surrounded by the PLA-g-MA, which limits the stiffening effect of MCC. Moreover, the presence of these agglomerates strongly reduces the elongation at break, entailing initiation of cracks during tensile tests.

Surprisingly, the influence of $\gamma$-irradiation has no significant effect on PLA/PLA-g-MA/MCC1, despite chain breaking has been highlighted. This can be explained by the role of interphase between PLA and MCC agglomerates surrounded by PLA-g-MA. The 

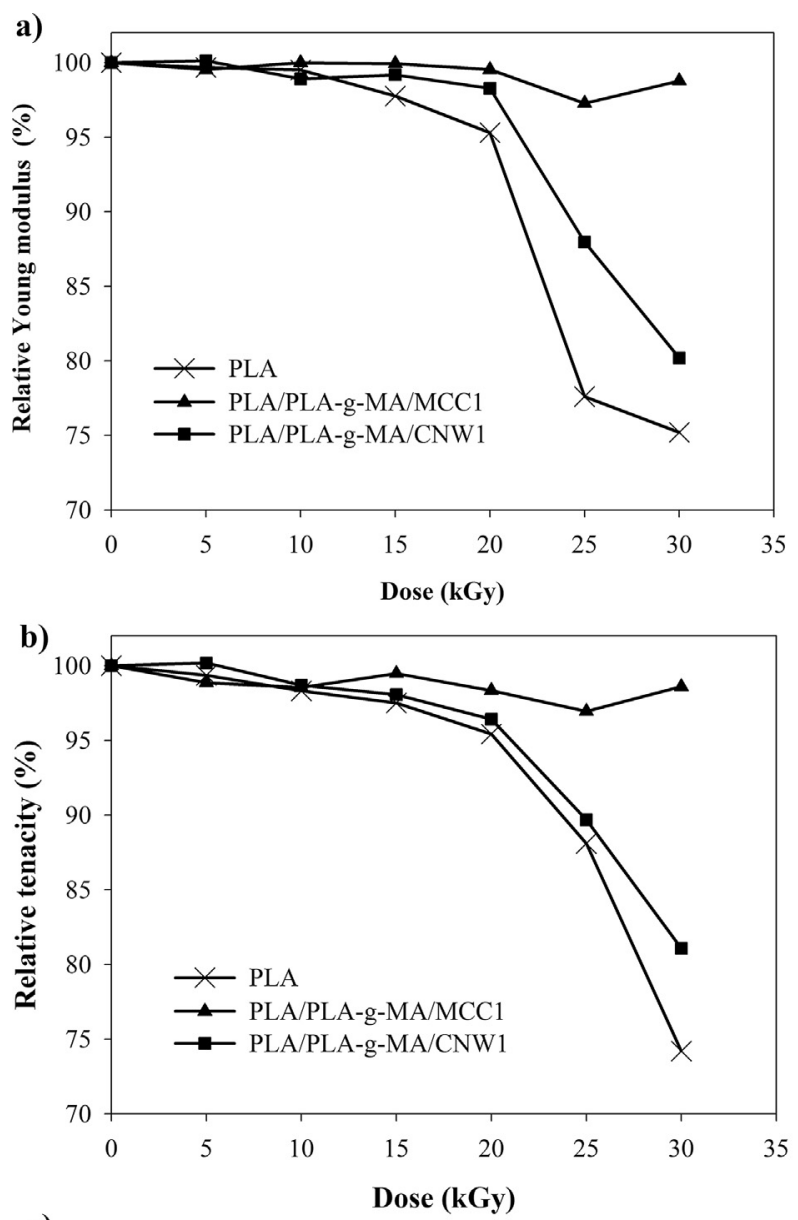

c)

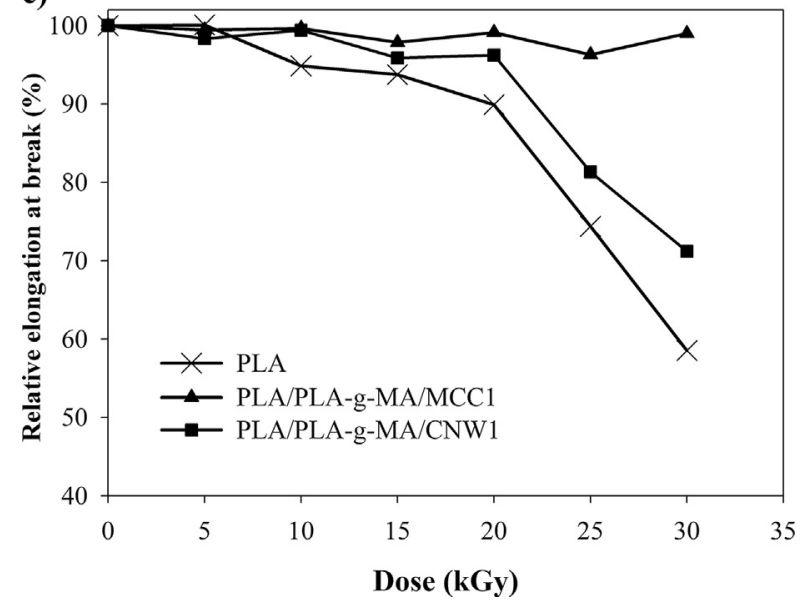

Fig. 6. Relative tensile properties of the fibers as function of $\gamma$-radiation dose; (a) Young modulus, (b) tenacity and (c) elongation at break.

mechanical properties continue to be governed by the soft behaviour of this interphase and the occurrence of less chain scissions in PLA. This explains the low influence of $\gamma$-irradiation on the mechanical properties, even at the highest radiation dose. Moreover, the crystalline nature of MCC tends to protect PLA and PLA-g-MA from the radiations by absorbing a part of the radiation energy.

Conversely, the good dispersion of CNW leads to a lower coverage with PLA-g-MA leading to a more rigid interface and the
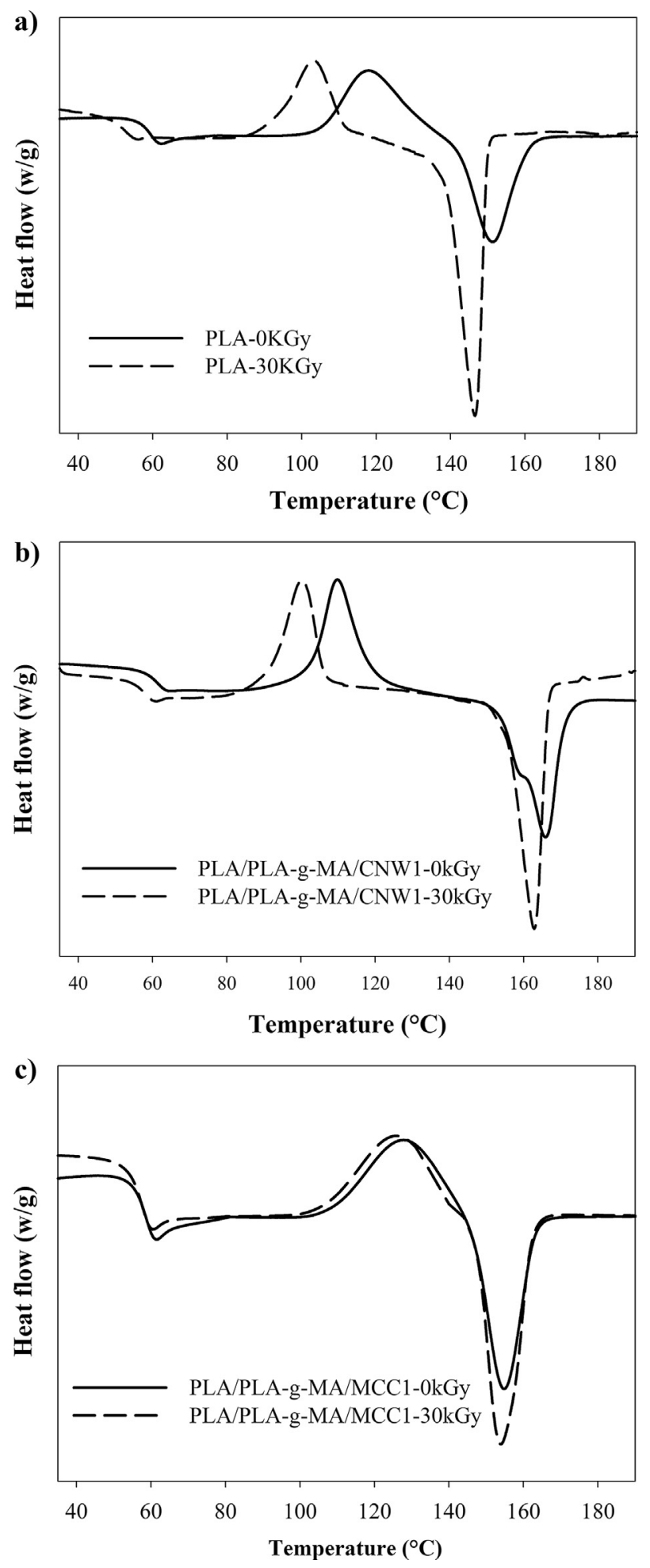

Fig. 7. DSC thermographs of (a) neat PLA, (b) PLA/PLA-g-MA/CNW1 and (c) PLA/PLA-g$\mathrm{MA} / \mathrm{MCC} 1$ recoded before and after irradiation of $30 \mathrm{kGy}$.

mechanical properties of the nanobiocomposite are more influenced by the chain distribution of PLA. Indeed after $30 \mathrm{kGy}$, the tensile characteristics values indicate a decrease by $20 \%$ in Young's modulus for irradiated PLA/PLA-g-MA/CNW1 compared to $25 \%$ for neat PLA, while the tenacity decreases by $19 \%$ for the nanobiocomposite compared to $26 \%$ for the matrix. 
Table 4

Thermal characteristics of neat PLA, PLA/PA-g-MA/MCC1 and PLA/PA-g-MA/CNW1 as a function of absorbed dose.

\begin{tabular}{|c|c|c|c|c|c|c|}
\hline \multirow[t]{2}{*}{ Fibers } & \multirow[t]{2}{*}{ Dose (kGy) } & \multirow[t]{2}{*}{$\mathrm{T}_{\mathrm{g}}\left({ }^{\circ} \mathrm{C}\right)$} & \multirow[t]{2}{*}{$\mathrm{T}_{\mathrm{cc}}\left({ }^{\circ} \mathrm{C}\right)$} & \multicolumn{2}{|l|}{$\mathrm{T}_{\mathrm{f}}\left({ }^{\circ} \mathrm{C}\right)$} & \multirow[t]{2}{*}{$\mathrm{X}_{\mathrm{c}}(\%)$} \\
\hline & & & & $\mathrm{T}_{\mathrm{f} 1}$ & $\mathrm{~T}_{\mathrm{f} 2}$ & \\
\hline \multirow{7}{*}{ PLA } & 0 & 58.6 & 117.3 & 151.3 & - & 0.5 \\
\hline & 5 & 58.3 & 116.7 & 150.5 & - & 2.8 \\
\hline & 10 & 57.6 & 115.2 & 150.5 & - & 3.7 \\
\hline & 15 & 57.2 & 114.4 & 150.0 & - & 4.3 \\
\hline & 20 & 57.0 & 113.3 & 149.7 & - & 8.3 \\
\hline & 25 & 55.0 & 111.5 & 148.8 & - & 9.8 \\
\hline & 30 & 51.1 & 103.2 & 147.2 & - & 15.0 \\
\hline \multirow[t]{7}{*}{ PLA/PLA-g-MA/MCC1 } & 0 & 58.8 & 127.4 & 154.8 & - & 1.8 \\
\hline & 5 & 58.8 & 127.4 & 154.8 & - & 1.9 \\
\hline & 10 & 58.4 & 125.5 & 154.3 & - & 2.2 \\
\hline & 15 & 58.5 & 125.4 & 153.3 & - & 2.5 \\
\hline & 20 & 58.2 & 124.5 & 151.7 & - & 2.9 \\
\hline & 25 & 58.5 & 124.7 & 153.8 & - & 3.1 \\
\hline & 30 & 57.6 & 124.1 & 153.6 & - & 3.4 \\
\hline \multirow[t]{7}{*}{ PLA/PLA-g-MA/CNW1 } & 0 & 61.5 & 111.6 & 158.40 & 165.8 & 5.3 \\
\hline & 5 & 60.5 & 110.1 & 158.73 & 165.3 & 5.5 \\
\hline & 10 & 60.3 & 109.4 & 158.91 & 164.3 & 6.9 \\
\hline & 15 & 59.6 & 108.8 & 158.37 & 165.0 & 11.0 \\
\hline & 20 & 59.8 & 108.4 & - & 164.5 & 12.3 \\
\hline & 25 & 59.1 & 107.5 & - & 164.3 & 12.1 \\
\hline & 30 & 56.2 & 100.3 & - & 162.8 & 13.7 \\
\hline
\end{tabular}

\subsection{Thermal properties}

\subsubsection{Differential scanning calorimetry analysis}

The radiation-induced changes on the thermal properties of the fibers were investigated by differential scanning calorimetry (DSC). Different DSC thermograms were recorded for the non-irradiated and irradiated PLA at $30 \mathrm{kGy}$, as shown in Fig. 7(a), (b) and (c). The thermal characteristics determined from the DSC thermograms for all samples are reported in Table 4.

DSC data summarized in Table 4 indicate that $\gamma$-irradiation significantly affects the different thermal transitions of neat PLA. This is well illustrated in Fig. 7(a) which shows that the DSC thermograms of non-irradiated and those of irradiated PLA exhibit different shapes, peak positions and areas due probably to structural changes occurred in the amorphous/crystalline fractions as a result of $\gamma$-irradiation [45]. Further, in Table 4, a decrease in the values of glass transition temperature $\left(T_{g}\right)$, cold crystallization temperature $\left(\mathrm{T}_{\mathrm{cc}}\right)$ and melting temperature $\left(\mathrm{T}_{\mathrm{m}}\right)$ of neat PLA is observed with increasing the radiation dose. This is due probably to the chain scission resulting in the formation of short polymer chains. The latter have a greater mobility inducing the occurrence of a disorder phase at lower temperature $[43,59]$. This is consistent with the literature data [27,43-47]. Moreover, the PLA crystallinity increases along the $\gamma$-irradiation process as shown in Table 4 . Indeed interaction between the $\gamma$-rays and PLA results in chain scission and consequently, the short chains promote the formation of crystallites with smaller size [33]. This is consistent with the data reported by D. Milicevic et al. [45].

Furthermore, Table 4 shows also that for the irradiated nanobiocomposite samples a thermal alteration is also observed with increasing the absorbed dose, being however less pronounced compared to that of neat PLA. Indeed at $30 \mathrm{kGy}$, the values of $\mathrm{T}_{\mathrm{g}}, \mathrm{T}_{\mathrm{cc}}$, and $\mathrm{T}_{\mathrm{m}}$ of neat PLA decrease by about 7,14 and $4{ }^{\circ} \mathrm{C}$, respectively, while those of PLA/PLA-g-MA/CNW1 fibers are reduced by almost 5 , 11 and $3^{\circ} \mathrm{C}$, respectively. In addition, Fig. 7(c) shows that the DSC curves corresponding to PLA/PLA-g-MA/MCC1 fibers, before irradiation and after $30 \mathrm{kGy}$, were quite close and DSC curves overlap. For the highest radiation dose, it can be noted that the rate of PLA crystallinity increases for both neat PLA and PLA/PLA-g-MA/CNW1,
Table 5

TGA data for neat PLA. PLA/PLA-g-MA/MCC1 and PLA/PLA-g-MA/CNW as a function of absorbed dose.

\begin{tabular}{lllll}
\hline Fibers & Dose $(\mathrm{kGy})$ & $\mathrm{T}_{5 \%}\left({ }^{\circ} \mathrm{C}\right)$ & $\mathrm{T}_{50 \%}\left({ }^{\circ} \mathrm{C}\right)$ & Char at $600{ }^{\circ} \mathrm{C}(\%)$ \\
\hline PLA & 0 & 316 & 360 & 0.60 \\
& 5 & 317 & 360 & 0.70 \\
& 10 & 313 & 359 & 1.03 \\
& 15 & 312 & 359 & 0.67 \\
& 20 & 308 & 355 & 0.86 \\
& 25 & 301 & 353 & 1.01 \\
PLA/PLA-g-MA/MCC1 & 0 & 296 & 350 & 0.98 \\
& 30 & 327 & 362 & 0.70 \\
& 5 & 326 & 360 & 0.86 \\
& 10 & 325 & 361 & 0.94 \\
& 15 & 327 & 362 & 0.78 \\
& 20 & 325 & 360 & 0.92 \\
PLA/PLA-g-MA/CNW1 & 0 & 319 & 358 & 1.50 \\
& 25 & 312 & 357 & 0.90 \\
& 30 & 332 & 363 & 0.10 \\
& 5 & 331 & 362 & 0.50 \\
& 10 & 330 & 363 & 0.20 \\
& 15 & 329 & 362 & 0.87 \\
& 20 & 328 & 360 & 0.56 \\
& 25 & 323 & 357 & 0.40 \\
& 30 & 322 & 356 & 0.88 \\
\hline
\end{tabular}

due to a chemicrystallization process resulted from chain breakings. This leads to the conclusion that the incorporation of MCC significantly increases the resistance of the nanobiocomposite towards $\gamma$-rays, despite their poor dispersion. However for PLA/CNW fibers, the low filler content ratio in PLA matrix could be probably the reason for a moderate increase in thermal resistance.

\subsubsection{Thermogravimetric analysis (TGA)}

TGA was used to investigate the thermal stability of neat PLA, PLA/PLA-g-MA/MCC1 and PLA/PLA-g-MA/CNW1 fibers under $\gamma$ irradiation. Table 5 provides the values of the main degradation temperatures for all fibers determined from TGA thermograms under nitrogen atmosphere.

TGA data in Table 5 clearly indicate that $\gamma$-irradiation decreases significantly the thermal stability of neat PLA. It is observed that the $\mathrm{T}_{5 \%}$ and $\mathrm{T}_{50 \%}$ values of neat PLA decrease by 20 and $10^{\circ} \mathrm{C}$, respectively after $30 \mathrm{kGy}$. This probably results from the decrease in molecular weight of the irradiated fibers due to chain scission. Thus, the polymer chains become more flexible/movable and, therefore, thermally less stable [60]. These results are in agreement with the literature data $[44,45]$.

For PLA/PLA-g-MA/MCC1 and PLA/PLA-g-MA/CNW1 fibers, similar trend as PLA fibers is also observed, which is characterized by a decrease in thermal stability as the radiation dose increases. However, the decrease in thermal stability of the nanobiocomposites is less pronounced compared to that of neat PLA. Indeed, the value of $\mathrm{T}_{5 \%}$ for PLA/PLA-g-MA/MCC1 and PLA/PLA- $g$ $\mathrm{MA} / \mathrm{CNW} 1$ decreases by 15 and $10^{\circ} \mathrm{C}$, respectively at $30 \mathrm{kGy}$, while that of neat PLA is reduced by $20^{\circ} \mathrm{C}$. This is most likely due to the higher decomposition of PLA chains that arise as radiolysis products, compared to that of nanobiocomposites.

\section{Conclusion}

In this study, it was demonstrated that $\gamma$-irradiation affects the chemical structure and properties of irradiated PLA and PLA/Cellulose fibers prepared by melt spinning. Indeed at $30 \mathrm{kGy}$, a significant decrease in molecular weight of the irradiated fibers was observed due to chain scission mechanism. Consequently, glass transition temperature, cold crystallization and thermal stability 
have also decreased. Tensile properties have been damaged only for pristine polymer and the composition containing cellulose nanowhiskers since in the case of the bionanocomposite with microcrystalline cellulose, the mechanical properties are essentially governed by the presence of PLA-g-MA at the matrix/nanofibre interface.

However, up to $20 \mathrm{kGy}$, the property changes of the irradiated fibers are almost negligible; accordingly, a dose of $20 \mathrm{kGy}$ could be accepted as an optimum dose of gamma rays for sterilization purposes of PLA fibers. Furthermore, it was also found that PLA is more sensitive to $\gamma$-irradiation than the nanobiocomposite samples, indicating the protective action of the cellulosic fillers and particularly MCC, due to its crystalline character. The capacity of cellulosic fillers to reduce the radiolytic degradation process in PLA fibers likely occurs by the formation of complex between reactive species of cellulose and PLA produced during $\gamma$-irradiation process.

\section{Acknowledgments}

T. Aouat would like to thank the Faculty of Technology of the University of Béjaïa in Algeria for its financial support and the technical staff members of ENSAIT Roubaix (France), C2MA-IMT (France) and CRNA (Algeria) for their contribution to this work.

\section{References}

[1] B. Gupta, N. Revagade, Poly(lactic acid) fiber : an overview, Prog. Polym. Sci. 32 (2007) 455-482.

[2] M. Persson, S.C. Mikael, The effect of process variables on the properties of melt-spun poly(lactic acid) fibres for potential use as scaffold matrix materials, J. Mater. Sci. 48 (2013) 3055-3066.

[3] K.M.Z. Hossain, A.J. Parsons, C.D. Rudd, I. Ahmed, W. Thielemans, Mechanical crystallisation and moisture absorption properties of melt drawn polylactic acid fibres, Eur. Polym. J. 53 (2014) 270-281.

[4] M. Savaris, V. Santos, R.N. Brandalise, Influence of different sterilization processes on the properties of commercial poly(lactic acid), Mater. Sci. Eng. C 69 (2016) 661-667.

[5] S. Solarski, M. Ferreira, E. Devaux, Ageing of polylactide and polylactide nanocomposite filaments, Polym. Degrad. Stabil. 93 (2008) 707-713.

[6] R. Rentenbergera, A. Cayla, T. Villmow, D. Jehnichen, C. Campagne, M. Rochery, et al., Multifilament fibres of poly( $\varepsilon$-caprolactone)/poly(lactic acid) blends with multiwalled carbon nanotubes as sensor materials for ethyl acetate and acetone, Sensor. Actuator. B Chem. 160 (2011) 22-31.

[7] P. Pötschke, T. Andres, T. Villmow, S. Pegel, H. Brünig, K. Kobashi, et al., Liquid sensing properties of fibres prepared by melt spinning from poly(lactic acid) containing multi-walled carbon nanotubes, Compos. Sci. Technol. 70 (2010) $343-349$.

[8] P. Bachelet, S. Solarski, M. Ferreira, E. Devaux, P. Coszach, M. Murariu, et al., Designing polylactide/Clay nanocomposites for textile applications : effect of processing conditions, spinning, and characterization, J. Appl. Polym. Sci. 109 (2008) 841-851.

[9] S. Solarski, F. Mahjoubi, M. Ferreira, E. Devaux, (Plasticized) polylactide/clay nanocomposite textile: thermal, mechanical, shrinkage and fire properties, J. Mater. Sci. 42 (2007) 5105-5117.

[10] M. Persson, G.S. Lorite, S. Cho, J. Tuukkanen, M. Skrifvars, Melt spinning of poly(lactic acid) and hydroxyapatite composite fibers: influence of the filler content on the fiber properties, Appl Mater Interfaces 5 (2013) 6864-6872.

[11] T. Aouat, M. Kaci, E. Devaux, C. Campagne, A. Cayla, L. Dumazert, et al., Morphological, mechanical, and thermal characterization of poly(lactic acid)/ cellulose multifilament fibers prepared by melt spinning, Adv. Polym. Technol. 37 (2018) $1-13$.

[12] M. Jorfi, E.J. Foster, Recent advances in nanocellulose for biomedical applications, J. Appl. Polym. Sci. 132 (2015) 1-19.

[13] S. Pirani, H.M.N. Abushammala, R. Hashaikeh, Preparation and characterization of electrospun PLA/nanocrystalline cellulose-based composites, J. Appl. Polym. Sci. 130 (2013) 3345-3354.

[14] Q. Shi, C. Zhou, Y. Yue, W. Guo, Y. Wu, Q. Wu, Mechanical properties and in vitro degradation of electrospun bio-nanocomposite mats from PLA and cellulose nanocrystals, Carbohydr. Polym. 90 (2012) 301-308.

[15] C. Zhou, Q. Shi, W. Guo, L. Terrell, A.T. Qureshi, D.J. Hayes, et al., Electrospun bio-nanocomposite scaffolds for bone tissue engineering by cellulose nanocrystals reinforcing maleic anhydride grafted PLA, Appl Mater Interfaces 5 (2013) 3347-3854.

[16] C. Xiang, A.G. Taylor, J.P. Hinestroza, M.W. Frey, Controlled release of nonionic compounds from poly(lactic acid)/cellulose nanocrystal nanocomposite fibers, J. Appl. Polym. Sci. 127 (2012) 79-86.

[17] D. Liu, X. Yuan, D. Bhattacharyya, The effects of cellulose nanowhiskers on electrospun poly(lactic acid) nanofibres, J. Mater. Sci. 47 (2012) 3159-3165.

[18] J.J. Blaker, K. Lee, M. Walters, M. Drouet, A. Bismarck, Aligned unidirectional PLA/bacterial cellulose nanocomposite fibre reinforced PDLLA composites, React. Funct. Polym. 85 (2014) 185-192.

[19] K.M.Z. Hossain, M.S. Hasan, D. Boyd, C.D. Rudd, I. Ahmed, W. Thielemans Effect of cellulose nanowhiskers on surface morphology, mechanical properties, and cell adhesion of melt-drawn polylactic acid fibers, Biomacromolecules 15 (2014) 1498-1506.

[20] S. Dadbin, F. Naimian, Gamma radiation induced property modification of poly(lactic acid)/hydroxyapatite bio-nanocomposites, Polym. Int. 63 (2014) 1063-1069.

[21] C. Fracalossi, R. Corte, K. Dua, I. Satiko, T. De Jesus, A. Pinto, Impact of sterilization methods on electrospun scaffolds for tissue engineering, Eur. Polym. J. 82 (2016) 181-195.

[22] S. Lanzalaco, S. Campora, V. Brucato, F. Carfi, E. Rosalia, D. Leonardo, et al. Sterilization of macroscopic poly(l-lactic acid) porous scaffolds with dense carbon dioxide : investigation of the spatial penetration of the treatment and of its effect on the properties of the matrix, J. Supercrit. Fluids 111 (2016) 83-90.

[23] A. Pegoretti, L. Fambri, C. Migliaresi, In vitro degradation of poly(L-lactic acid) fibers produced by melt spinning, J. Appl. Polym. Sci. 2 (1997) 213-223.

[24] M. Ma, W. Zhou, Improving the hydrolysis resistance of poly(lactic acid) fiber by hydrophobic finishing, Ind. Eng. Chem. Res. 54 (2015) 2599-2605.

[25] S. Dadbin, Y. Kheirkhah, Gamma irradiation of melt processed biomedical PDLLA/HAP nanocomposites, Radiat. Phys. Chem. 97 (2014) 270-274.

[26] R. Dorati, C. Colonna, M. Serra, I. Genta, T. Modena, F. Pavanetto, et al., $\gamma$ -irradiation of PEGd, IPLA and PEG-PLGA multiblock copolymers : I . Effect of irradiation doses, Am Assoc Pharm Sci 9 (2008) 718-725.

[27] M.C. Gupta, V.G. Deshmukh, Radiation effects on poly(lactic acid), Polymer 24 (1983) 827-830.

[28] D.I. Braghirolli, D. Steffens, K. Quintiliano, G.A. Xavier Acasigua, D. Gamba, R.A. Fleck, C.L. Petzhold, PP, The effect of sterilization methods on electronspun poly(lactide-co-glycolide) and subsequent adhesion efficiency of mesenchymal stem cells, J. Biomed. Mater. Res. B Appl. Biomater. 102 (2014) $700-708$.

[29] F. Sefat, R. Mckean, P. Deshpande, C. Ramachandran, C.J. Hill, V.S. Sangwan, et al., Production, sterilisation and storage of biodegradable electrospun PLGA membranes for delivery of limbal stem cells to the cornea, Procedia Eng 59 (2013) 101-116.

[30] I. Krucinska, O. Chrzanowska, M. Bogun, M. Kowalczuk PD, Fabrication of PLGA/HAp and PLGA/PHB/HAp fibrous nanocomposite materials for osseous tissue regeneration, Autex Res. J. 14 (2014) 95-110.

[31] M. Schnabelrauch, R. Wyrwa, H. Rebl, C. Bergemann, B. Finke, M. Schlosser, et al., Surface-coated polylactide fiber meshes as tissue engineering matrices with enhanced cell integration properties, Int J Polym Sci 2014 (2014) 1-12.

[32] T.A.M. Valente, D.M. Silva, P.S. Gomes, M.H. Fernandes, J.D. Santos, V. Sencadas, Effect of sterilization methods on electrospun poly(lactic acid) (PLA) fiber alignment for biomedical applications, Appl Mater Interfaces 8 (2016) 3241-3249.

[33] L. Zaidi, S. Bruzaud, M. Kaci, A. Bourmaud, N. Gautier, Y. Grohens, The effects of gamma irradiation on the morphology and properties of polylactide/Cloisite 30B nanocomposites, Polym. Degrad. Stabil. 98 (2013) 348-355.

[34] I. Zembouai, M. Kaci, S. Bruzaud, L. Dumazert, A. Bourmaud, M. Mahlous, et al., Gamma irradiation effects on morphology and properties of PHBV/PLA blends in presence of compatibilizer and Cloisite 30B, Polym. Test. 49 (2016) 29-37.

[35] A. Marra, A. Boumail, S. Cimmino, P. Criado, C. Silvestre, M. Lacroix, Effect of $\mathrm{PLA} / \mathrm{ZnO}$ packaging and gamma radiation on the content of, J Food Sci Eng 6 (2016) 245-259.

[36] L. Petersson, I. Kvien, K. Oksman, Structure and thermal properties of poly(lactic acid)/cellulose whiskers nanocomposite materials, Compos. Sci. Technol. 67 (2007) 2535-2544.

[37] J. Brozek, V. Benesova, L. Malinova, R. Kalouskova, Stability of poly(L-lactic acid) in textile applications, Polym. Adv. Technol. 25 (2014) 934-939.

[38] C. Remili, M. Kaci, S. Kachbi, S. Bruzaud, Y. Grohens, Photo-oxidation of polystyrene/clay nanocomposites under accelerated UV exposure : effect on the structure and molecular weight, J. Appl. Polym. Sci. 112 (2009) $2868-2875$.

[39] J. Milanovic, M. Kostic, P. Milanovic, P. Skundric, Influence of TEMPOmediated oxidation on properties of hemp fibers, Ind. Eng. Chem. Res. 51 (2012) 9750-9759.

[40] E. Fortunati, I. Armentano, Q. Zhou, D. Puglia, A. Terenzi, L.A. Berglund, et al., Microstructure and nonisothermal cold crystallization of PLA composites based on silver nanoparticles and nanocrystalline cellulose, Polym. Degrad. Stabil. 97 (2012) 2027-2036.

[41] P.D. Nair, K. Sreenivamn, M. Jagabahn, Multiple gamma radiation sterilization of polyester fibres, Biomaterials 9 (1987) 335-338.

[42] A. Bakken, N. Boyle, B. Archambault, A. Hagen, N. Kostry, K. Fischer, et al. Thermal and ionizing radiation induced degradation and resulting formulation and performance of tailored poly(lactic acid) based hot melt adhesives, Int. J. Adhesion Adhes. 71 (2016) 66-73.

[43] D. Milicevic, S. Trifunovic, J. Dojcilovic, N. Ignjatovic, E. Suljovrujic, The influence of gamma radiation on the molecular weight and glass transition of PLLA and HAp/PLLA nanocomposite, Nucl. Instrum. Methods Phys. Res. B 268 (2010) 2744-2749.

[44] T.J. Madera-Santana, R. Melendrez, G. Gonzalez-Garcia, P. Quintana-Owen, 
S.D. Pillai, Effect of gamma irradiation on physicochemical properties of commercial poly(lactic acid) clamshell for food packaging, Radiat. Phys. Chem. 123 (2016) 6-13.

[45] D. Milicevic, S. Trifunovic, S. Galovic, E. Suljovrujic, Thermal and crystallization behaviour of gamma irradiated PLLA, Radiat. Phys. Chem. 76 (2007) $1376-1380$.

[46] T. Yovcheva, M. Marudova, A. Viraneva, E. Gencheva, N. Balabanov, G. Mekishev, Effect of gamma-irradiation on the electret properties of poly(Llactide), J. Appl. Polym. Sci. 128 (2013) 139-144.

[47] P. Nugroho, H. Mitomo, F. Yoshii, T. Kume, Degradation of poly(L-lactic acide) by gamma irradiation, Polym. Degrad. Stabil. 72 (2001) 337-343.

[48] Y. Kodama, L.D.B. Machado, C. Giovedi, K. Nakayama, Gamma radiation effect on structural properties of PLLA/PCL blends, Nucl. Instrum. Methods Phys. Res. B 265 (2007) 294-299.

[49] T. Huq, A. Khan, F.M.J. Hossain, T. Akter, U. Haydar, N. Aktar, et al., Gammairradiated jute/polypropylene composites by extrusion molding, Compos. Interfac. 20 (2013) 93-105.

[50] R.A. Khan, S. Beck, D. Dussault, S. Salmieri, J. Bouchard, M. Lacroix, Mechanical and barrier properties of nanocrystalline cellulose reinforced poly(caprolactone) composites: effect of gamma radiation, J. Appl. Polym. Sci. 129 (2013) 3038-3046.

[51] S.B.S. Raghavendra, B. Vindo, L.J. Sudev, Effect of gamma irradiation on mechanical properties of natural fibers reinforced hybrid composites, Int J Sci Technol Eng 2 (2015) 15-23.

[52] J.M. Islam, M.A. Hossan, F. Alom, M.I.H. Khan, M.A. Khan, Extraction and characterization of crystalline cellulose from jute fiber and application as reinforcement in biocomposite : effect of gamma radiation, J. Compos. Mater. 51 (2017) 31-38.

[53] A. Fernandez, M.D. Sanchez, M. Ankerfors, J.M. Lagaron, Effects of ionizing radiation in ethylene-vinyl alcohol copolymers and in composites containing microfibrillated cellulose, J. Appl. Polym. Sci. 109 (2008) 126-134.

[54] K. Melski, H. Kubera, W. Głuszewski, Effect of ionizing radiation on the properties of PLA packaging materials, Nukleonika 56 (2011) 65-69.

[55] S. Salmieri, F. Islam, R.A. Khan, Antimicrobial nanocomposite films made of poly(lactic acid)-cellulose nanocrystals (PLA-CNC) in food applications-part B : effect of oregano essential oil release on the inactivation of listeria monocytogenes in mixed vegetables, Cellulose 21 (2014) 4271-4285.

[56] C.-S. Wu, Renewable resource-based composites of recycled natural fibers and maleated polylactide bioplastic: characterization and biodegradability, Polym. Degrad. Stabil. 94 (2009) 1076-1084.

[57] E.S. Arau, H.J. Khoury, S.V. Silveira, Effects of gamma-irradiation on some properties of durolon polycarbonate, Radiat. Phys. Chem. 53 (1998) 79-84.

[58] M.F. Zaki, Y.H. Elshaer, D.H. Taha, The alterations in high density polyethylene properties with gamma irradiation, Radiat. Phys. Chem. 139 (2017) 90-96.

[59] L.M. Oliveira, E.S. Araújo, S.M.L. Guedes, Gamma irradiation effects on poly(hydroxybutyrate), Polym. Degrad. Stabil. 91 (2006) 2157-2162.

[60] N. Touati, M. Kaci, H. Ahouari, Y. Grohens, The effect of $\gamma$-Irradiation on the structure and properties of poly(propylene)/clay nanocomposites, Macromol. Mater. Eng. 292 (2007) 1271-1279. 